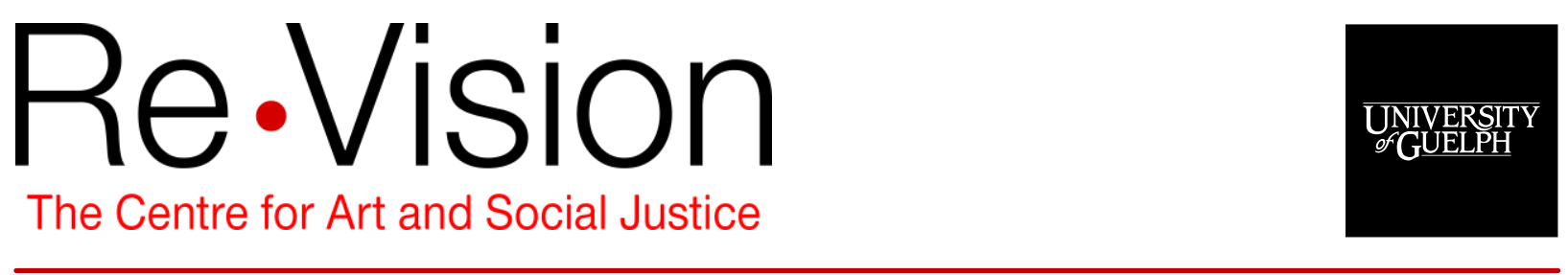

\title{
Doing justice to intersectionality in research
}

Carla Rice

University of Guelph

Elisabeth Harrison

York University

May Friedman

Ryerson University

\section{Recommended citation:}

Rice, C., Harrison, E., \& Friedman, M. (2019). Doing justice to intersectionality in research. Cultural Studies <-> Critical Methodologies. https://doi.org/10.1177/1532708619829779 


\section{Doing Justice to Intersectionality in}

\section{Research}

Carla Rice, Elisabeth Harrison, May Friedman

\section{Abstract}

Intersectionality involves the study of the ways that race, gender, disability, sexuality, class, age, and other social categories are mutually shaped and interrelated through forces such as colonialism, neoliberalism, geopolitics, and cultural configurations to produce shifting relations of power and oppression. The concept does not always offer a clear set of tools for conducting social research. Instead, it offers varied strands of thought, pointing to different methodologies and methods for doing intersectional research. In this article, we trace the genealogy of intersectionality as theory and methodology to identify challenges in translating the concept into research methods, and we review debates about what we identify as three "critical movements" in the intersectionality literature, comprising contestations regarding the theory's aims, scope, and axioms, in scholarship and research. Finally, we consider how these critical movements can offer researchers some guiding ethical principles for doing intersectionality justice in social research.

Keywords intersectionality, social justice, methodology, feminist theory, praxis, research ethics

\section{Introduction}

Intersectionality has emerged over the last decade as one of feminism's most significant contributions to social research. Developed over 30 years ago by African American feminist and critical race scholars to overcome exclusion in second-wave feminism, 
intersectionality has since been adapted by scholars seeking to consider the multiple "axes" of power and difference that shape individuals' positionalities (Brah \& Phoenix, 2004). Today, intersectionality involves the study of how race, gender, disability, sexuality, class, and other social categories are mutually shaped and interrelated with broader historical and global forces such as colonialism, neoliberalism, geopolitics, and cultural configurations to produce shifting relations of power and oppression (Hobbs \& Rice, 2011; Hobbs \& Rice, 2018). The concept does not always offer a clear blueprint for conducting research; instead, it offers varied strands of thought pointing to different methodologies for doing intersectional research. As intersectionality gains traction in the social sciences, some scholars are concerned that its social justice impetus may be deflated when it is used merely to manage complexity in research. It is the contention of this article that social justice and a move toward social transformation must be at the center of any research that calls itself intersectional. While social justice and transformational change may be broadly defined, we argue that research that aims to remain true to the radical inception and richly divergent implications of intersectionality as a cultural theory requires a deep commitment to decolonizing, anti-racist, feminist, and other liberatory scholarships and movements.

In this article, we trace the genealogy of intersectionality to pinpoint challenges identified by critical researchers in following the analytic's theoretical twists and turns, and in upholding its radical focus in research. We review recent debates in intersectionality scholarship and identify three critical movements regarding its aims, scope, and axioms in research. These movements foreground debates and developments in the literature that can aid researchers in designing methodological approaches that uphold intersectionality's radical roots while engaging with its evolving meanings. Our aim in introducing scholars to this landscape of debates is to invite greater consideration of what a focus on a justice-oriented understanding of intersectionality and its rhizomatic movement might mean for those who apply the term to their research. We contend that because intersectionality remains a work in progress, it is vital that researchers engage with the field's key debates and developments, and reckon with the theory's diverging and sometimes irreconcilable meanings and applications to do justice to and with it. Developing familiarity with the terrain of 
intersectionality studies will enable researchers to identify their theoretical startingpoints and assemble the most appropriate methodology for their research, while keeping in mind the main through-line of the analytic itself: an orientation to social justice and transformational change.

\section{Where We Begin}

This project emerged out of invitations that one of the authors of this article, Rice, has repeatedly received to review applications for research funding competitions. Drawing on her experiences with two decades of critical research sitting in the intersections of gender, disability, madness, class, and embodiment, Rice was dismayed to find an increasing move toward use of the term "intersectionality" without any meaningful engagement with debates in the field or substantiation from the term's critical focus. Instead, research projects were employing additive approaches to consider the characteristics of two or more social markers without considering complexities which emerged at these junctures, and without acknowledgement of the broader social context in which identities and differences are considered and constructed. She brought her concerns to Harrison and Friedman and a conversation emerged in which we collectively considered three things: first, what deeply held beliefs underpinned our understanding of intersectionality; second, how we "know it when we see it"-how we identify critical intersectionality research or that which we believe falls short; and third, the term's scholarly genealogy that has led us to our current, critical understanding.

To understand our relationship to intersectionality, we needed to delve into not only the origins of the term but also into our own origins. We are three differently positioned critical scholars who have been conducting intersectional research in the areas of disability, gender, race, embodiment, and "mental health" for a combined 35 years; over this time, we have grappled with questions surrounding the ethical and practical application of the theory in our research. Rice and Harrison are White while Friedman is racialized; Rice has close ties to Indigenous kin. We all identify to varying degrees as middle class with working class roots, as living with mental or physical disability, and as queer. We are each often understood as non-normatively embodied. Obviously, this 
short description minimizes the complexity of our lives, our experiences, and our relationships with and beyond one another. In part, this is why we have worked to translate intersectionality theory into methodology while working on a number of intersectional research projects (Rice, 2014; Rice, 2018; Rice, Chandler, Harrison, Ferrari \& Liddiard, 2015; Rice, Chandler, Liddiard, Rinaldi \& Harrison, 2018; Rice, Chandler, Rinaldi, Liddiard, Changfoot, Mykitiuk, \& Mundel, 2017; Rinaldi, Rice, LaMarre, Pendleton Jiménez, Harrison, Friedman, et al 2016). This body of research is deeply embedded in our experiences walking through the world as explicitly intersectional beings; the more research we do, the more we see that all social problems require a critical engagement with intersectionality. As we have undertaken research, we have confronted a persistent gap in the intersectionality literaturenamely, guidance for researchers translating its various strands of thought into methodologies without compromising the theory. By offering a theoretically grounded, praxis-oriented, and thoroughly interdisciplinary overview of the topic, this article is our contribution to filling that gap. We invite readers into the conversation we have begun, a conversation that considers the tangible characteristics of methodologies that take on intersectionality's radical potential and grapples with its explicitly transformative impetus.

In centering interdisciplinarity, our article seeks to bridge another gap: the growing divide between cultural studies scholarship which theorizes, and methodologicallydriven research which deploys the construct in practice. A close reading of intersectional scholarship invites empirical researchers to examine principles underlying research design, practices of conducting research, and questions of in whose interests any given research is undertaken. Similar to the mandate of this journal, this article aims to bring critical scholarship into conversation with methodological inquiry to interrupt tendencies in empirical research toward instrumentalization, flattening, and depoliticizing of thick theoretical concepts. Finally, we seek to show how cut critically intersectional research can animate theory in ways that honor the origins of intersectionality itself-its rootedness in the lived experiences of Black women situated at the nexus of multiple intersecting oppressions. 


\section{Method}

In developing our analysis, we searched relevant databases (Proquest and Google Scholar) for the terms "intersectionality" and "theory" or "methodology," and identified promising articles. We excluded works that discussed intersectionality only tangentially, and included texts that proffered arguments about intersectionality as theory and methodology, eventually compiling a list of 98 sources (not all of which are cited due to space limitations and, for other reasons, which we explicate below). Beginning with commonly cited works, we identified texts considered as originary or impactful and used these to develop a genealogical map of debates in the field. Digesting the literature as a whole and reading texts from different disciplines in relation to each other, we identified recurring rubs and their metamorphoses over time. We distilled these rubs into "critical movements" and analyzed how they worked together, developing a conceptual framework for understanding the literature through an interdisciplinary frame. We then revisited the literature to check the trustworthiness, quality, and rigor of this framework and revised the analysis (Golafshani, 2003). Any topology is limited in how it flattens nuanced arguments, but we believe that this approach is useful—and original—in how it brings together humanities and social science approaches, and identifies relevant strands in debates for the purposes of understanding what is happening in the field and in its uptake (or lack of uptake) in empirical research as a whole.

\section{Genealogies and Developments: Origins of Intersectionality}

Intersectionality has its roots in Black feminist thought, spanning the work of 19thcentury anti-slavery and women's rights activist Sojourner Truth through to contemporary Anglo-Black feminists (Alexander-Floyd, 2012). In her speech at the 1851 Women's Rights Convention in Akron, Ohio, Truth gestured toward intersectionality as she described her life at the nexus of colliding gender, class, and race inequalities as a once-enslaved African woman. Many other Black women theorists and activists, including the 19th-century African American thinkers like theologian Maria Stewart and educator Anna Julia Cooper, and late 20th-century theorists like Angela Davis, Audre Lorde, and members of the Black lesbian Combahee River Collective, have spoken and 
written in opposition to the exclusion of Black women from the cultural imaginary and in women's and civil rights movements.

In 1989, Black feminist legal scholar Kimberlé Crenshaw first named and developed intersectionality as a theory and analytic tool. Thinking through the limits and distortions of "single-axis" approaches to discrimination, Crenshaw (1991) argues that theories of discrimination that failed to account for multiple marginalizations "relegated the identity of women of color to a location that resists telling" (p. 1242). She employed the metaphor of an intersection to describe how Black women experience discrimination in ways similar to White women's and Black men's oppressions, in doubled ways that combine the effects of sexism and racism, and in distinctive ways emerging from colliding oppressions. Sociologist Patricia Hill Collins (2000) follows by identifying in Black feminist thought the unique traditions of focusing on social justice and Black women's lives, writing that social theories developed by multiply marginalized women ". . . reflect women's efforts to come to terms with lived experiences within intersecting oppressions" (p. 9). She introduced the idea of the "matrix of domination" to describe the social organization of Black women's lives "in which intersecting oppressions originate, develop, and are contained" (p. 228) to highlight the necessity of recognizing the intersecting structural dimensions of lived oppression.

Intersectionality is rooted in materialism or structuralism, but from 1990 onward, intersectionality scholars increasingly employed poststructuralism to theorize entanglements of difference, power, the emergence of categories in contradictory relations, and individuals' resistance through and against categorization (Brah \& Phoenix, 2004). Theorists in feminist studies and related fields have also brought intersectionality into conversation with other social theories, including queer theory (Fotopoulou, 2012; Hahner, 2012), mestizaje/mestiza consciousness (Lugones, 1994), and the new materialism (Geerts \& van der Tuin, 2013). Many of these discussions have focused on reconciling structuralist and poststructuralist theory or resolving the problem of subjectivity and identity, seeking anti-essentialist approaches to subjectivity and group affiliation. Within the social sciences, intersectionality has been used to study micro-level experiences and macro-level interactions between groups, their structural 
placement, and their representation in discourses. In developing intersectionality research, researchers have adapted many methods-surveys, statistical analyses, indepth interviews, case studies, ethnographic and narrative methods, and discourse analysis.

Critical scholars across disciplines and theoretical perspectives have embraced intersectionality, with some approaching it as a theory, others as a methodology, and others still as a resource for tackling social analysis. In what follows, we focus on intersectionality's changing meanings and divergent mobilizations since its original conceptualization. Here, our aim is not to resolve debates but to map out how and where intersectionality has spread, theoretically and methodologically, to become a "feminist success story" (Davis, 2008, p. 67). As such, we approach the three movements that we identify as emblematic rather than unique: They are key moments in an ongoing topography of debate and scholarship, but they are moments that expose the field's major nuances and frictions, rubs that researchers must contend with to credibly call their research intersectional.

\section{Critical Movements}

Beyond critical race and feminist scholarship, researchers have broadened and adapted intersectionality to engage wide-ranging issues, power dynamics, and discursive fields. As a far-reaching theory, intersectionality has generated controversy and critique. We describe these contestations as "critical movements," to capture how intersectionality theory has dispersed across scholarly disciplines, social differences, and sociopolitical issues and to encapsulate how the debates have shifted according to the speaker, their intellectual/political investments, and their discursive terrain.

We use the phrase "critical movements" to describe intersectionality's theoretical and methodological twists and turns because movement denotes motion and speaks to how the debates we identify shift in relation to each other. It also has resonances with movements to promote social change, which aligns with our goal of calling on researcher-scholars to engage with social justice movements and center justice in their 
work. To that end, we consider how the critical movements we identify might offer researchers some guiding ethical principles for doing justice to intersectionality in research. We do not forward one definitive methodology of intersectionality; instead, we argue that to do intersectionality justice, researchers must unequivocally orient to issues of power, positionality, and difference throughout their research processes. Other scholars have done close readings of theoretical texts and mapped topologies of the field; by contrast, here, we provide a pathway through the debates to make sense of the theory's multiple and sometimes incommensurate directions and developments to suggest practical ways of engaging with the theory methodologically while doing justice to and with it.

We identify three critical engagements with intersectionality's theoretical and methodological developments: aims, scope, and axioms. While these frameworks offer a means of distinguishing strands of contestation-namely, who intersectionality is for, what its purposes are, how it might be operationalized, and what its main assumptions are-they are nevertheless fluid, messy, non-linear, and overlapping. Our discussion is informed by Jennifer Nash's (2016) cautions concerning "intersectional originalism"where scholars engage in close readings of intersectionality's foundational texts as a means of constructing their own interpretation of the theory's meaning, objective, and scope. Nash argues that calls to "safeguard" intersectionality from appropriation often fail to attend to the "political and institutional questions" (p. 18) shaping its widespread uptake across universities, which are corporate, neoliberal institutions with "rhetorical investment[s] in diversity, difference, and inclusion" (p. 10). Following Nash, we seek to foreground the political contexts of the critical movements we consider.

\section{Aims: Managing Complexity and Making Change}

Researchers' deployment of intersectionality to manage complexity rather than understand/change oppression is emerging as a major point of contestation concerning the theory's uptake in research. Nikol Alexander-Floyd (2012) asserts that, to be applied with integrity, intersectional research must retain its "focus on illuminating women of color as political subjects and the gender, racial, class, and sexual politics that impact 
their lives" (p. 19) and deploy research methods that authorize marginalized voices and de-center the experiences/interests of privileged groups. In contrast, Hill Collins and Bilge (2016) maintain that as social justice is intersectionality's "most contentious core idea" (p. 30), it should not be a requirement for intersectional research. Our view is that appropriating intersectionality erases Black intellectual efforts to crystalize Black women's experiences into theory. Politically, it elides that intersectional analyses arose not from isolated imaginations but from Black women's grounded efforts to name intersecting oppressions in their lives to change them. Sirma Bilge (2013) describes erasure of this history as part of a trend toward "depoliticizing intersectionality" (p. 405) to whiten it and eliminate its function as a tool for political change. Depoliticization also animates intersectionality's adoption by some social scientists undertaking what Jasbir Puar (2012) calls "diversity management" (p. 53), where, as Bilge (2013) explains, researchers co-opt the language of intersectionality but fail to undertake intersectional analysis or to challenge inequalities. As under neoliberalism, "identity-based radical politics are often turned into corporatized diversity tools leveraged by dominant groups to attain . . . institutional goals" (p. 407), researchers must resist opportunistic uses of intersectionality in favor of developing ethical, politically-grounded approaches to truly collaborative research and counter-hegemonic knowledge production. Intersectionality as a complexity-management tool need not focus exclusively on Blackness or on women, but it must orient to interrogating the dynamics of power and oppression that are typified by a reckoning with its origins in Black feminist thought. In other words, the aims of intersectional research must be grounded in the term's founding purpose.

Leading intersectionality scholars have noted that the field continues to lack a welldefined methodology, rigorous methods for examining difference and power, and evaluated practices for conducting multi-category and multi-level research (McCall, 2005). The sheer volume of methodologies proposed for conducting intersectional research underscores the discrepancy between the theory and its application. Floya Anthias (2013b) suggests that the scale of intersectional research design is difficult to determine; for example, should researchers study "social ontologies" (the categories that give rise to social relations) or the construction and maintenance of these divisions (gender, race) in structures? Saliency in intersectional research design, Anthias 
suggests, is also problematic; how many differences (e.g., race, gender, class, disability) should be incorporated into a given study, which are most relevant, and are they always equally salient? Finally, Anthias (2013a) shows that intersecting oppressions cannot always be interpreted as strengthening each other; rather, the effects of mutual constitution are better understood as "dialogical and contradictory" ( $p$. 129).

Nonetheless, many researchers have incorporated intersectionality as methodology. Where some have used the construct to understand inner psychic life and micro-level experiences (Fotopoulou, 2012; Hahner, 2012), others have employed it to analyze macro-level structural and cultural configurations (Crenshaw, 1991; McCall, 2005). In revealing the common interests of specific groups of people, these projects show that categories can be inclusive and politically useful. By analyzing the relation of positionalities to broader social structures and historical geopolitical processes, they demonstrate intersectionality's potential to rise above identitarian logics and the centering of identities/selves over social configurations. Intersectionality has become an important analytic device for researchers to interrogate how their allegiances affect research processes, to unmask how their positions of privilege/disadvantage influence their research, and to explore the dynamic and contradictory workings of power. While intersectionality's application to research remains as unstable and dynamic as the term itself, self-conscious awareness of its origins and a deeply held commitment to radical social transformation nonetheless must maintain a consistency across critically intersectional research.

\section{Scope: Appropriation and Applicability}

Since intersectionality's formulation in Black feminist thought, some have claimed the concept as primarily about Black women's experiences; others have aimed to extend intersectionality to new social issues, subject formations, and theoretical domains; still others have questioned its utility due to its ostensible divisiveness; while still others have ignored the theory's origins by rewriting its genealogy based on their affiliations. For example, Nina Lykke (2011) argues that European feminists have thought 
intersectionally as far back as Alexandra Kollontai, the early 20th-century Russian feminist revolutionary; Marcel Stoetzler (2016) argues that intersectionality originates with German social psychologist Moritz Lazarus and sociologist Georg Simmel; and Ange-Marie Hancock (2007) claims American feminist anarchist Emma Goldman's work included intersectionality. To meaningfully engage with the scope of intersectionally directed methodologies, it is necessary to interrogate the ideas/impulses that underpin these contested claims.

At first glance, such historical re-telling could be seen to reflect the embrace of a resonant idea; however, some proponents have made the theory over in their own image. Maria Carbin and Sara Edenheim (2013) discuss the tendency to retroactively apply the label of intersectionality to obfuscate the racism of White feminist theory. Gail Lewis (2013) similarly maintains that intersectionality's appropriation in the European academy serves as a means of disavowing racism within that academy. For Nash (2016), any argument that stresses intersectionality's importance "by re-making the analytic apart from black women's bodies" must be questioned, as such a move implies that "an analytic centered on black women [would] not be palatable or desirable as a field-defining analytic" (p. 17). Indeed, researchers in long-standing disciplines may have difficulty adopting intersectionality as an analytic because of their disciplines' ongoing rootedness in Euro-Western frameworks and methodologies. These dynamics explain, in part, why scholars may have rewritten the genealogy of intersectionality: to downplay its focus on social transformation from the racialized, sexualized bottom-up to better align with dominant knowledge systems in their field.

Rather than extending the analytic, some theorists, notably Naomi Zack (2005), argue for discarding it entirely, contending that intersectionality's emphasis on differences is divisive in how it prevents people with shared identities from working together effectively. Here and elsewhere, intersectionality is seen as promoting "identity politics" and forestalling coalition building (Cho, 2013, p. 292). Others, however, embrace the analytic as a means of enabling people to establish shared interests and solidarity across differences to resist oppression (Falcón, 2012; Ferguson, 2010). Indeed, in her foundational essays, Crenshaw presents a roadmap for coalition-building by 
demonstrating how single-axis approaches foreclose possibilities for solidarity. Following Crenshaw's understanding of identity as inherently coalitional, Anna Carastathis (2016) explains that recognizing identities as "internally heterogeneous, complex unities constituted by their internal differences and dissonances and by internal as well as external relations of power" (p. 7) helps scaffold coalitional work. As dialogue across difference is difficult, Nira Yuval-Davis $(1997,2011)$ recommends traversal practices of rooting and shifting: Here, researchers interrogate their own histories/positionalities while opening to and gaining fluency in others' histories/contemporary conditions of oppression and struggle. This is a critical activity for any research that claims to be intersectional.

Much recent work in intersectionality views it as universally applicable, describing the relationship between oppression and privilege and locating people and groups at specific positions along multiple axes. Sumi Cho, Kimberlé Crenshaw, and Leslie McCall (2013) point out that the theory was conceived as a generally applicable means of understanding oppression and privilege and how multiple dimensions of power crosscut all social groups. Acknowledging this, some theorists advise that intersectional approaches necessitate the analysis of the marked and unmarked positions of social agents to ensure that power relations and privileged categories do not remain unnamed and under-theorized in their work (Anthias, 2013a). A recognition of power is thus essential to undertake critically intersectional methodologies. Far from narrowing intersectionality's scope, such an approach not only restores the wide applicability of intersectionality as a methodological direction but also acknowledges the ways that intersectionality is always political.

\section{Axioms: Stasis and Change}

Some critics claim that given its roots in structuralism, intersectionality frames identities and subjectivities as static, coherent entities, and therefore is unable to accommodate a multiplicity of identities or theorize subjectivities as relational and emergent. However, others view the theory as provisional, open-ended, and flexible in its understanding and mapping of identity and subjectivity. The latter view might consider identity formation as 
a predictable, traceable, and knowable process occurring through the confrontation of differences with forces of domination. The former position might characterize subjectivities and social forces as processual, dynamic, and contingent, therefore unmappable and unpredictable, knowable only through their effects in/through people. The maturing of the term and its applicability to research require an understanding of the tensions bound in considering intersectionality as simultaneously constituting and complicating social identities and identity politics.

Sustained challenges to intersectionality have emerged from queer theory. Employing poststructuralist claims concerning the contingency of identity, for example, Leslie Hahner (2012) maintains that intersectionality should be conceptualized not as the confrontation of coherent, stable identities, but rather as the "constitutive relationship between discourse and subjectivity" (p. 152). She names this "constitutive intersectionality" and asserts it can account for how identifications shift in response to situations. Aristea Fotopoulou (2012) similarly identifies two ways of undertaking intersectional research: one in which deconstructing categories is central, and the second in which categories are employed "critically, strategically and selectively" (p. 24).

Others have engaged with decolonial thought, mestizaje/mestiza consciousness, the new materialism, and Deleuzian assemblage theory to resolve continuing controversies over the character, limitations, and implications of intersectionality. Anna Carastathis (2016) notes that a decolonial perspective cannot be accounted for by including additional axes of difference in an intersectional analysis; instead, decolonization demands the fundamental transformation of ideology, institutions, and relationships to resources and land. In a critical response to Crenshaw's intersectionality metaphor, Ann Garry (2011) introduces the image of a mountain with varied liquids running down it, mixing and pooling at different locations. She connects this with María Lugones's mestizaje/mestiza concepts of "purity/splitting" and "impurity/curdling" as different approaches to understanding subjectivity and sociality. Distinguishing the mestiza logic of impurity/multiplicity from the Eurocentric logic of purity/unity, Lugones (1994) explains that the latter creates fragmented identities for people at intersections while allowing those who claim purity to occupy and validate the normative (White male) subject 
position. The unitary rational subject conceptualizes himself as disembodied and unmarked by difference and constructs his fictional self against the rejected fragments of those he understands as Other (imagined as more embodied, marked, hybrid). Garry and Lugones both argue in favor of an intersectionality theory that draws from impurity/curdling logics to interrogate identity constitution in relation to dominant paradigms.

Among those bringing intersectionality into conversation with the new materialism are Evelien Geerts and Iris van der Tuin (2013). In intersectional theory, they argue, power functions mainly as a restrictive force, leaving undertheorized how it productively enables agency and resistance. New materialist thought offers a solution to this conundrum in how it reconceptualizes social forces and subjectivities as "materialdiscursive phenomena" that agentically shift and change each other through their continuous confrontation (Barad \& DeKoven, 2001, p. 95, quoted in Geerts and van der Tuin 2013, p. 176). Finally, Jasbir Puar (2012) reframes intersectionality through the Deluezian concept of "assemblage"-a complex and dynamic series of events-to capture processes of self and social formation in more dynamic ways than that of intersection. For Puar (2007), understanding intersectionality as "a series of dispersed but mutually implicated and messy networks, draw[ing] together enunciation and dissolution, causality and effect, organic and nonorganic forces" (pp. 211-112) foregrounds how subjectivities and socialities are always interchanging and changing. These theoretical pairings hold promise for the ways they can account for the constraining and productive functions of power as well as the indeterminacy and unpredictability of structures and categories.

Practically speaking, critical intersectional research must attend to theoretical tensions regarding the stability versus instability, or the structural versus processual character of subjectivities and social worlds. The term's origins require an acknowledgement of and reckoning with the axiomatic make-up of subjectivities and social realities, and the relationships of these terms to power, oppression, resistance, and agency. Simultaneously, extensions of the term and the work of contemporary intersectionality scholars expose the dynamic, unstable nature of social ontologies. Critical intersectional 
methodologies must thus expose identities, subjectivities, structures, and processes as "working truths" while simultaneously exploring and exposing the power relations that make, unmake, and remake them.

\section{Doing Just Research}

What counts as intersectional research and what criteria should determine what counts? Sifting through the debates, we reject the argument that intersectional approaches should only be used by a particular social group and advocate instead that intersectionality is for a particular purpose: justice. The degree to which a knowledgemaking project embraces social justice is our standard for gauging the degree to which it enacts intersectionality in exemplary or problematic ways. And while we acknowledge that the word "justice" has been deployed in as many ways as the term "intersectionality," we feel that a view of intersectionality that acknowledges the deep need for social transformation and maintains an awareness of privileges and oppressions commits to a broad sense of justice. In our view, it is appropriative to adopt intersectionality without acknowledging its origins in the work of Black feminist scholarship. Thus, recognition of and meaningful engagement with the intellectual work of Black women is one ethical criterion that informs this standard. We further argue that it does intellectual disservice to coopt the parts of a theory that are compatible with existing structures and power relations (for the technical work the theory does in managing complexity) while ignoring aspects of the theory that orient to intervening in those structures and relations to liberatory ends. Thus, a second ethical criterion is engaging in citation and research practices that disrupt the political status quo across social structures and academic disciplines.

In what follows, we employ the critical movements described above to suggest ways that intersectional research can be enacted to create new perspectives on and pathways to justice. We outline three strategies for researchers conducting intersectional research that are grounded in these movements and guided by the principle of justice that animates intersectionality. We deliberately use composite examples from social research to make a case for the strategies we have identified and 
to highlight problematic and exemplary instances of intersectionality in action. We have chosen to avoid identifying particular research examples because it is our intention to engage with exemplars, not to single out particular researchers. The examples that we choose inevitably reflect our positionalities and interests (and hence we use those from embodiment, mental health, and disability-related research) and are therefore limited and partial. We are confident, however, that other researchers applying the analysis developed here will find similar examples in their areas of interest.

\section{"Speaking Into the Void": Centering Liberatory Objectives and Preventing}

\section{Misappropriation}

Critical intersectionality is dynamic and versatile: It underlines multiple dimensions of identities/subjectivities, stresses that every dimension of identity/subjectivity is related to structures of power and has potential to create liberatory change by demonstrating how interactions between social locations and power structures manifest in oppression and privilege. To avoid undermining the liberatory objectives at its core, however, it is essential to avoid "misogynoir" (misogyny directed toward Black women; Bailey, 2010) by explicitly recognizing the concept's creation by Kimberlé Crenshaw, its basis in Black feminist thought, and the location of Black women's experiences as central and paradigmatic.

Some scholars, such as Bilge (2013), argue for re-centering race, racializing processes, and racial privilege in intersectionality research. Yet how do we as researchers, especially those of us who are beneficiaries of racial, settler/colonial, or abled privilege, account for our positionalities in knowledge systems and the social realities we help to shape? Critical self-reflexivity is one way to grapple with this problem. Many White scholars do not consciously see themselves or their conceptual frameworks as raced or racist; nor do non-disabled scholars often recognize processes of ableism that underpin their investments in certain knowledge systems. To disrupt such ignorance, we might place ourselves on the same critical analytic plane as participants by asking, "What do I recognize, and not recognize, because of the positions I occupy?" Reflexivity disrupts power relations embedded in acts of naming and narrating others from the top down 
and allows space for research to be understood as a dynamic process that transforms researchers and participants. We might also pose questions of ourselves that seem irrelevant to the present study to discover the boundaries of and silences surrounding a topic, precisely because we are all located in racist and ableist systems and data collection/interpretation always operates within these networks of power.

We have experienced in our own research how intersectional approaches can enable differently located individuals and groups to think/feel deeply about their privilege and/or disadvantage with respect to the differential positioning of each other and the issues at hand. Such reflexivity can facilitate cross-movement building and political change through clarifying how privilege operates, how structures of power and oppression interrelate, and how justice struggles are interlinked throughout research and activist efforts. We have also experienced how tensions surface and emotions become stuck when people challenge each other to develop consciousness of privileges and inequalities as these materialize in research. As Lewis (2013) contends, where these dynamics and the underlying justice issues to which they point remain unaddressed, power relations become impermissible to talk about, silencing aggrieved groups and, paradoxically, rendering the "toxic effects" of issues such as racialization as unspeakable and "emotionally alive" (p. 884). The unspoken issues do not disappear but haunt the project and produce their own material effects.

Giving voice to struggles related to conferred privilege and enforced subordination might be understood as part of the process of creating a politicized community in an area of inquiry and action. May (2014) notes that "because privilege often leads to 'blank spots' (Anzaldúa 1990) and willful ignorance" (p. 95), it becomes politically necessary for aggrieved groups to "speak into the void" (May, quoting Crenshaw, 2011, p. 288) of the dominant imaginary to challenge what counts as credible knowledge and who can know. Thinking with May and Anzaldúa, we venture that what may be required of the privileged is the willingness to suspend all investments and to open to the embodied testimony of the other in radically undefended ways. Although carrying risks—of getting it wrong, of psychic harm, of continued symbolic/systemic oppression, and, ultimately, of failure-speaking from and hearing out of the void can facilitate politically potent 
collaborations. It may be the best method researchers have for building inclusive theoretical perspectives and transformative movements from divided, asymmetrical interests. It creates space for perspectives to emerge from the bottom-up, which challenges the elitism of the academy and processes of research and knowledge production "as usual."

Silvia Bettez (2015) writes, "when researchers are reflexive, we are attentive to how our experiences, knowledge, and social positions might impact . . . the research process" (p. 940). Transversal politics as described above is rooted in standpoint epistemology, the notion that our knowledge is limited, shaped by our unique experiences. The difficulty with practicing transversalism is that our capacity for self-knowledge is thus necessarily limited. To proceed with this work, we must also practice accountability. As Falcón and Nash (2015) write, our intersectional work should be shaped by an ethos of "generosity and multitude rather than singularity and certitude" (p. 9).

It is possible to deploy intersectional analysis to achieve non-progressive and even reactionary ends, though to do so is to disregard its liberatory purposes. For example, some psychology researchers have defined intersectionality as the study of how multiple identity categories interact to produce varied perceptions of inequality among individuals. This definition - without further reference to intersectionality's genealogywas used in a study concerning the mental health of Black youth in the United States, which concluded that perceptions of racism are correlated with increased risk of depression for some and recommended that mental health supports should target the most vulnerable groups. Given the authors' use of an intersectional framework, it is problematic that their sole recommendation was to encourage the medicalization of those experiencing distress due to their recognition of an oppressive political reality. ${ }^{1}$

Carastathis (2016) asserts that intersectionality should be engaged as a provisional concept intended to change our thinking, rather than an end in itself. She concludes, and we agree, that widespread misappropriation of the concept as a signifier of ethical

\footnotetext{
1 We deliberately avoid citing the examples of problematic research discussed here because we view these as emblematic rather than uniquely flawed. We do not seek to scapegoat particular researchers for what we view as a broader concern about the ways that intersectionality is commonly deployed.
} 
and/or methodological quality even within research rooted in perspectives that validate and perpetuate colonialism, racism, and sexism demonstrates the fallaciousness of claims that intersectionality's potential or utility has been exhausted. While intersectionality's methodological flexibility may increase the likelihood of misappropriation, we maintain that researchers who remain rooted in and mindful of its purposes and origins can mitigate this tendency, whether in conducting their own or in reviewing others' research.

\section{Developing Theoretically Informed Methods and Theorizing Categories}

Because there is no consensus as to how the concept should be applied, intersectionality is sometimes viewed as difficult to implement or even non-viable. If we center the concept's genealogy as a means of understanding oppression to challenge it, we might better recognize it as open-ended rather than vague, applicable to many forms of social analysis. Its methodological flexibility may make it particularly viable, as it can illuminate inequality at multiple scales. Intersectionality's adaptability makes it suitable for diverse methodological applications, qualitative and quantitative; however, its analytical flexibility also predisposes it to misapplication. Whether the concept is used in qualitative or quantitative research, we assert that to prevent intersectionality's misappropriation, community interests must be centered, and diverse voices from aggrieved communities must be considered in formulating research and analyzing results. Undertaking intersectional research does not mean that researchers can or should account for every possible social position and shifting intersection. However, for work to be meaningfully intersectional, it should address historical and contemporary social/cultural forces through a political lens. Intersectional research can take place at multiple analytical levels - micro, mezzo, and macro—but it is neither necessary nor ideal to address in detail every dimension of each level. Nonetheless, it is important to address why some levels and dimensions are the subject of focus, explaining what types of analysis might be facilitated and which might be limited as a result.

But how do we identify which social categories make a difference in a particular context? Attention might be given to exploring which categories illuminate the 
differences that matter in a given situation. Researchers could also ask themselves what might be achieved by using intersectionality to analyze the social field under investigation. Olena Hankivsky (2014) argues that in undertaking intersectional research, no "before the fact" assumptions may be made as to the relative importance of any given intersection. In contrast, David Gillborn (2015) argues for the salience of race as a primary category of analysis, citing his research on racism in English schools, where racism clearly functions as a central organizing principle. Some quantitative researchers contend that analyzing the impact of particular variables across intersections can demonstrate which factor has the greatest influence, which could be useful when determining a course of action to address a social problem (Bright, Malinsky, \& Thompson, 2016). Method selection must be guided by context, in accordance with the objective of achieving social justice. Intersectionality cannot be understood as simply a technology; to do so is to negate its genealogy.

In researching groups at the margins, feminist and other critical researchers typically turn to qualitative methods. Many claim that these aid in analyzing social locations as intersections because they can account for subjectivities at the nexus of multiple registers of privilege/inequality. Some theorists, including McCall, argue for applying intersectionality in quantitative research to bring forth dimensions of social life not discernible through individual experience. Liam Kofi Bright et al. (2016) also advocate a methodologically pluralistic approach to intersectional research, arguing that although qualitative methods can gather rich information about participants' lives, such studies often rely on assumptions about which people experience marginalization, whereas quantitative researchers can reduce sample bias by recruiting participants who may or may not be marginalized. Furthermore, because quantitative methods can demonstrate causal relationships, policy makers may favor quantitative findings. Quantitative design represents an opportunity for understanding the "big picture"; however, it also poses a challenge for intersectional analysis as it typically approaches categories as fixed variables and generates statistical results that reify categories as static or homogeneous. The statistical data produced reaffirm categories created during research design, which may leave little room for these to be disrupted/deconstructed throughout the research. To mitigate this problem, we suggest that quantitative 
intersectional researchers deploy strategic essentialism (Spivak, 1996), recognizing as a limitation of their research that any account of identities, relationalities, structures, culture, and so forth will be partial and subject to change.

Researchers should consider how categories can differ across time and place. Ramon Grosfoguel, Laura Oso, and Anastasia Christou (2015) note that constructions of race and racism vary widely across societies; so researchers must attend to the contextual specificities of their construction. The meaning of a category can also vary for individuals who belong to it. As Jeanne Marecek (2016) writes, "If social categorizations are contingent and their meanings always provisional, we need to exercise caution when we use them as buckets for sorting research participants. Such buckets will always be in danger of leaking or even blowing apart" (p. 180). We found an instance of this problem in a study concerning trans people's mental health. Researchers claimed that they used an inclusive definition of trans in conducting their survey, but ultimately categorized all participants as "female-to-male" (FTM) or "male-to-female" (MTF). Genderqueer and non-binary participants were sorted into the two categories, with those assigned female at birth categorized as FTM and those assigned male at birth categorized as MTF. The fact that genderqueer and non-binary identities generally do not fit this trajectory was not acknowledged as a serious limitation of this research.

To deal with the problem of reification, Hancock (2007) shows how intersectionality can inform survey design without reifying differences by recording people's multiple group memberships and their level of affiliation with each group. This solution, however, elides a larger problem with the quantitative embrace of intersectionality: that the concept was devised for aggrieved groups to understand and combat inequities shaping their lives, not to manage difference in research. Researchers who are committed to scientific objectivity risk ignoring how their analyses might undercut justice principles. Due to the distance between researcher and researched characteristic of quantitative and/or positivist methodologies (even where analyses are ostensibly developed in service of justice-seeking groups), problems and solutions can be framed in ways that undermine the people being studied. For example, policy research engaging with intersectionality sometimes takes up fatphobic, "obesity epidemic" discourses. Such research does not 
acknowledge or engage with the work of critical obesity and fat studies scholars, referring instead to positivistic research taking for granted the notion that fat people's bodies are problematic, while also leaving unconsidered the intersections of fatphobia with racism, classism, and colonialism.

Intersectional analysis captures some aspects of a political situation at a specific time. Each of the conceptual pairings discussed above-with queer theory, mestizaje/mestiza consciousness, the new materialism, and Deleuzian assemblage theory-can open lines of inquiry for intersectionality while helping researchers to develop new theories of subjectivity and sociality. Similarly, Cho et al. (2013) reimagine intersectionality as a field of study, "more as a nodal point than as a closed system-a gathering place for open-ended investigations of the overlapping and conflicting dynamics of race, gender, class, sexuality, nation, and other inequalities" (p. 788). The notion of intersectionality as a "gathering place" can accommodate the pairings proposed by critical theorists, which offer new insights into the interplay of difference and inequality and new avenues for response. Approaching intersectionality in this way helps to avoid reification of categories and of intersectionality itself and creates a conceptual and political space for new identities, social formations, and ways of researching the social world.

\section{Working Within, Without, and Beyond}

As the practice of transversalism shows, intersectionality is not divisive but enables recognition of difference. While acknowledging difference can surface conflicts and tension, working in coalition necessitates honestly addressing disparities, imbalances, mistakes, and failures. Hailed by neoliberal logics that value productivity and success, researchers learn to hide failure; in this climate, admitting failure opens us to uncomfortable conversations and emotions, political challenges, career impasses, and the unsettling of expertise. Yet from a social justice vantage, it is critical that we orient to mistakes and failure as productive. Whether we fail to anticipate differences or recognize privileges, failure creates the conditions of possibility for vulnerability and, with it, greater understanding and learning. Moreover, because many researchers are embedded in research institutions, which, as Falcón and Nash (2015) explain, "[rely] on 
competition of resources, on exclusions, on divisions shaped by the white supremacist capitalist patriarchy" (p. 6), it is vital that intersectional researchers work to resist cooptation. Intersectional research must account for the political and institutional contexts shaping it, including recognizing characteristics of the universities and granting agencies gatekeeping research, which shape how-and what-research is done, and the political contexts shaping the lives of participants, including how these influence participation.

In our experience, funding bodies increasingly emphasize knowledge creation with immediate "real world" effects, encouraging researchers to partner with practitioners in sectors such as business, health, and education who may have direct impacts on their systems and the public. This trend is informed by the neoliberal emphasis on rapid and measurable impacts/outcomes. By developing coalitions rooted in principles of equity and reciprocity with activist movements and progressive organizations, researchers can reterritorialize partnership, support necessary social change endeavors, and resist commodification. The recent move of some large state-sponsored funding bodies in the Anglo-West and Europe to support large research collaborations involving multiple community, institutional, and disciplinary partners complicates this picture insofar as funded collaborations, though ripe with possibilities for generating counter-hegemonic knowledge and liberatory change, also tend to bureaucratize research, lessen researcher transparency, and value "problem-free" processes over messy, problemattuned social justice approaches.

\section{Conclusion}

In this article, we have provided those new to intersectionality theory and those conducting and evaluating research that purports to be intersectional with an overview and critical analysis of interdisciplinary debates most relevant to its methodological application. We hope that this will serve as a resource for people seeking to take up intersectionality in their research projects in ways consistent with its ethos. In our view, to do justice to intersectionality, researcher-scholars must respect its foundations with Crenshaw's groundbreaking work and its roots in Black feminist thought and engage in 
citation practices that do justice to the theory's genealogy. As intersectionality continues to develop through the intellectual work of its originators and others, and through debate and its placement in conversation with other perspectives, it is critical that we regard it as much more than a technology for managing complexity in research. The dynamics of identity and the social world are necessarily complex, but the theory was developed in the interest of Black women to understand and combat inequities shaping people's lives. There is no single ideal method for undertaking intersectional research. It can be used with many methods and approaches, quantitative and qualitative. At the same time, intersectionality reinforces the necessity of researcher reflexivity and attention to power relations at all levels. Intersectionality theory enables researchers to account for the multiplicity and situatedness of identity, enabling us to recognize the interplay of our many commonalities and differences.

Although feminist and critical scholars disagree in their critiques of the ways intersectionality has been deployed in research, they often agree on an essential quality of intersectional research: intersectionality orients to social justice, so research utilizing intersectional analysis must commit to justice in its processes and knowledge production. Because intersectionality theory has been applied to diverse strategies for managing multiple data points in research, contradictory perspectives regarding its practical application persist. We argue that every dimension of a research project is an opportunity to work toward social justice. Intersectionality deals with the complexity and messiness of lives, relationships, structures, and societies, so data collection and analysis methods must be responsive to contexts and serve liberatory objectives. Thus, in our view, the animating consideration for critical researchers in undertaking intersectional research is one of continuously and unequivocally interrogating at every stage of the process, "Am I doing justice?"

\section{Declaration of Conflicting Interests}

The author(s) declared no potential conflicts of interest with respect to the research, authorship, and/or publication of this article. 


\section{Funding}

The author(s) disclosed receipt of the following financial support for the research, authorship, and/or publication of this article: This study was funded by Canada Research Chair's Program (CRC) 950-231091.

\section{References}

Alexander-Floyd, N. G. (2012). Disappearing acts: Reclaiming intersectionality in the social sciences in a post-black feminist era. Feminist Formations, 24, 1-25.

Anzaldúa, G. (1990). Haciendo caras, una entrada. In Anzaldúa, G. (Ed.), Making face, making soul/Haciendo caras: Creative and critical perspectives by feminists of color (pp. xv-xxvii). San Francisco: Aunt Lute.

Anthias, F. (2013a). Hierarchies of social location, class and intersectionality: Towards a translocational frame. International Sociology, 28, 121-138.

Anthias, F. (2013b). Intersectional what? Social divisions, intersectionality and levels of analysis. Ethnicities, 13, 3-19.

Bailey, M. (2010). They aren't talking about me. The Crunk Feminist Collective. Retrieved from http://www.crunkfeministcollective.com/2010/03/14/they-arent-talkingabout-me/

Bettez, S. C. (2015). Navigating the complexity of qualitative research in postmodern contexts: Assemblage, critical reflexivity, and communion as guides. International Journal of Qualitative Studies in Education, 28, 932-954.

Bilge, S. (2013). Intersectionality undone: Saving intersectionality from feminist intersectionality studies. Du Bois Review: Social Science Research on Race, 10, 405424.

Brah, A., Phoenix, A. (2004). Ain't I a woman? Revisiting intersectionality. Journal of International Women's Studies, 5, 75-86. 
Bright, L. K., Malinsky, D., Thompson, M. (2016). Causally interpreting intersectionality theory. Philosophy of Science, 83, 60-81.

Carastathis, A. (2016). Intersectionality: Origins, contestations, horizons. Lincoln: University of Nebraska Press.

Carbin, M., Edenheim, S. (2013). The intersectional turn in feminist theory: A dream of a common language? European Journal of Women's Studies, 20, 233-248.

Cho, S. (2013). Post-intersectionality: The curious reception of intersectionality in legal scholarship. Du Bois Review: Social Science Research on Race, 10, 385-404.

Cho, S., Crenshaw, K., McCall, L. (2013). Toward a field of intersectionality studies: Theory, applications, and praxis. Signs: Journal of Women in Culture and Society, 38, 785-810.

Collins, P. H. (2000). Black feminist thought: Knowledge, consciousness, and the politics of empowerment. London, England: Routledge.

Collins, P. H., Bilge, S. (2016). Intersectionality. Cambridge, UK: Polity Press.

Crenshaw, K. (1989). Demarginalizing the intersection of race and sex: A black feminist critique of antidiscrimination doctrine, feminist theory and antiracist politics. University of Chicago Legal Forum, 140, 139-167.

Crenshaw, K. (1991). Mapping the margins: Intersectionality, identity politics, and violence against women of color. Stanford Law Review, 43, 1241-1299.

Crenshaw, K. (2011.) Postscript. In Lutz, H., Herrera Vivar, M.T., Supik, L. (Eds.), Framing intersectionality: Debates on a multi-faceted concept in gender studies (pp. 221-234). Burlington, VT: Ashgate.

Davis, K. (2008). Intersectionality as buzzword: A sociology of science perspective on what makes a feminist theory successful. Feminist Theory, 9, 67-85. 
Falcón, S. M. (2012). Transnational feminism and contextualized intersectionality at the 2001 World Conference Against Racism. Journal of Women's History, 24, 99-120.

Falcón, S. M., Nash, J. C. (2015). Shifting analytics and linking theories: A conversation about the "meaning-making" of intersectionality and transnational feminism. Women's Studies International Forum, 50, 1-10.

Ferguson, A. (2010). How is global gender solidarity possible? In Jónasdóttir, A. G., Bryson, V., Jones, K. B. (Eds.), Sexuality, gender and power: Intersectional and transnational perspectives (pp. 243-258). London, England: Routledge.

Fotopoulou, A. (2012). Intersectionality queer studies and hybridity: Methodological frameworks for social research. Journal of International Women's Studies, 13, 19-32.

Garry, A. (2011). Intersectionality, metaphors, and the multiplicity of gender. Hypatia, 26, 826-850.

Geerts, E., van der Tuin, I. (2013). From intersectionality to interference: Feminist ontoepistemological reflections on the politics of representation. Women's Studies International Forum, 41, 171-178.

Gillborn, D. (2015). Intersectionality, critical race theory, and the primacy of racism: Race, class, gender, and disability in education. Qualitative Inquiry, 21, 277-287.

Golafshani, N. (2003). Understanding reliability and validity in qualitative research. The Qualitative Report, 8, 597-607.

Grosfoguel, R., Oso, L., Christou, A. (2015). "Racism", intersectionality and migration studies: Framing some theoretical reflections. Identities, 22, 635-652.

Hahner, L. A. (2012). Constitutive intersectionality and the affect of rhetorical form. In Chávez, K. R., Griffin, C. L. (Eds.), Standing in the intersection: Feminist voices, feminist practices in communication studies (pp. 147-168). Albany: State University of New York Press. 
Hancock, A. (2007). When multiplication doesn't equal quick addition: Examining intersectionality as a research paradigm. Perspectives on Politics, 5, 63-79.

Hankivsky, O. (2014). Rethinking care ethics: On the promise and potential of an intersectional analysis. American Political Science Review, 108, 252-264.

Hobbs, M., Rice, C. (2011). Rethinking Women's Studies: Curriculum, pedagogy, and the introductory course. Atlantis: Critical Studies in Gender, Culture \& Social Justice/Études critiques sur le genre, la culture, et la justice sociale, 35 (2), 139-149.

Hobbs, M., Rice, C. (2018). Mapping the terrain of Gender and Women's Studies. Gender and Women's Studies: Critical Terrain, 2nd edition (pp. xvii-xxix). Toronto, ON: Canadian Scholar's Press/Women's Press.

Lewis, G. (2013). Unsafe travel: Experiencing intersectionality and feminist displacements. Signs: Journal of Women in Culture and Society, 38, 869-892.

Lugones, M. (1994). Purity, impurity, and separation. Signs: Journal of Women in Culture and Society, 19, 458-479.

Lykke, N. (2011). Intersectional analysis: Black box or useful critical feminist thinking technology? In Lutz, H., Vivar, M. T. H., Supik, L. (Eds.), Framing intersectionality: Debates on a multi-faceted concept in gender studies (pp. 207-220). Farnham, UK: Ashgate.

Marecek, J. (2016). Intersectionality theory and feminist psychology. Psychology of Women Quarterly, 40, 177-181.

May, V. M. (2014). "Speaking into the void?" Intersectionality critiques and epistemic backlash. Hypatia, 29, 94-112.

McCall, L. (2005). The complexity of intersectionality. Signs: Journal of Women in Culture and Society, 30, 1771-1800. 
Nash, J. C. (2016). Feminist originalism: Intersectionality and the politics of reading. Feminist Theory, 17, 3-20.

Puar, J. K. (2007). Terrorist assemblages: Homonationalism in queer times. Durham, NC: Duke University Press.

Puar, J. K. (2012). "I would rather be a cyborg than a goddess": Becoming-intersectional in assemblage theory. Philosophia, 2, 49-66.

Rice, C. (2018). The spectacle of the child woman: Troubling girls in/and the science of early puberty. Feminist Studies, 44 (3), 535-566.

Rice, C. (2014). Becoming Women: The embodied self in image culture. Toronto: UT Press.

Rice, C., Chandler, E., Liddiard, K., Rinaldi, J., Harrison, E. (2018). The pedagogical possibilities for unruly bodies. Gender \& Education, 30(5), 663-682.

Rice, C., Chandler, E., Rinaldi, J., Liddiard, K., Changfoot, N., Mykitiuk, R., Mundel, I. (2017). Imagining disability futurities. Hypatia: A Journal of Feminist Philosophy, 32(2), 213-229.

Rice, C., Chandler, E., Harrison, E., Ferrari, M., Liddiard, K. (2015). Project Re•Vision: Disability at the edges of representation. Disability \& Society, 30(4), 513-527.

Rinaldi, J., Rice, C., LaMarre, A., Pendleton Jiménez, K., Harrison, E., Friedman, M., McPhail, D., Robinson, M., Tidgwell, T. (2016). "Through Thick and Thin”: Storying queer women's experiences of taking up and resisting idealized body images and expected body management practices. Psychology of Sexualities Review (PoSR), $7(2)$, 63-77.

Spivak, G. C. (1996). Subaltern studies: Deconstructing historiography. In Landry, D., MacLean, G. (Eds.), The Spivak reader (pp. 203-236). London, England: Routledge. 
Stoetzler, M. (2016). Intersectional individuality: Georg Simmel's concept of "The Intersection of Social Circles" and the Emancipation of Women. Sociological Inquiry, 86, 216-240.

Yuval-Davis, N. (1997). Gender and nation. London, England: Sage.

Yuval-Davis, N. (2011). The politics of belonging: Intersectional contestations. London, England: Sage.

Zack, N. (2005). Inclusive feminism: A third wave theory of women's commonality. Lanham, MD: Rowman \& Littlefield.

\section{Author Biographies}

Carla Rice is professor and Canada Research Chair at the University of Guelph specializing in embodiment studies and in creative methodologies. She founded Re•Vision: The Centre for Art and Social Justice as an arts-informed research centre with a mandate to foster inclusive communities, social well-being, equity, and justice. Rice has received awards for research, mentorship and advocacy, and has written on embodied difference, intersectionality, non-normative cultures, and accessibility and inclusion.

Elisabeth Harrison is a PhD candidate in Critical Disability Studies at York University, Toronto. Her dissertation research uses narrative and digital storytelling methods to illuminate trans, genderqueer, gender nonconforming and nonbinary people's experiences with mental health care in Ontario. She has taught courses in women and gender studies, psychology, and education. Her research interests are in Mad studies, fat studies, and intersectionality theory.

May Friedman's research looks at unstable identities, including bodies that do not conform to traditional racial and national or aesthetic lines. Most recently much of May's research has focused on intersectional approaches to fat studies considering the multiple and fluid experiences of both fat oppression and fat activism. May works at 
Ryerson University as a faculty member in the School of Social Work and in the Ryerson/York graduate program in Communication and Culture. 